Fecha de recepción: diciembre 2010

Fecha de aceptación: julio 2011

Versión final: marzo 2012

\section{La educación de los profesionales del cine: características y tensiones de un campo en formación}

María Torre ${ }^{\star}$

\begin{abstract}
Resumen: La enseñanza del cine ha adquirido ya un lugar dentro del campo de la educación superior: las licenciaturas en Realización de Cine y TV, el Diseño de Imagen y Sonido conviven, no sin tensiones, con las ya institucionalizadas carreras de Comunicación Social. Dentro del campo de los estudios sobre cine, la enseñanza no ha sido un tópico especialmente abordado, el presente artículo busca aproximarse a esta temática a partir de trazar una historia de la educación cinematográfica en el país que permita identificar continuidades y rupturas, y comprender, en base a la inscripción socio-histórica de este proceso, las resignificaciones ligadas a la enseñanza del cine siendo que es en esa trama donde emergen y se configuran las significaciones sociales vinculadas al cine.
\end{abstract}

Palabras clave: audiovisual - cine - enseñanza - universidad.

[Resúmenes en inglés y portugués en las páginas 129-130]

${ }^{(*)}$ Licenciada en Sociología (UBA). Cursó Maestría en Comunicación y Cultura (UBA). Becaria de postgrado del CONICET. Docente de la Universidad de Palermo y de la Universidad de Buenos Aires.

Este artículo constituye un avance de una investigación realizada en el marco de mi proyecto de tesis de Maestría en Cultura y Comunicación de la Facultad de Ciencias Sociales de la Universidad de Buenos Aires.

Hoy en día, la enseñanza del cine parece haber adquirido un lugar dentro del campo de la educación superior: las licenciaturas en Realización de Cine y TV, el Diseño de Imagen y Sonido conviven, no sin tensiones, con las ya institucionalizadas carreras de Comunicación Social. A lo largo del presente artículo nos proponemos dar cuenta de la historia de la enseñanza cinematográfica con el objetivo de identificar continuidades y rupturas, y comprender, en base a la inscripción socio-histórica de este proceso, las resignificaciones ligadas a la enseñanza del cine. ¿Qué implicancias supuso la institucionalización de la enseñanza del cine?, ¿quiénes fueron los agentes encargados de llevar adelante estas iniciativas?, ¿sobre qué discursos se fundamentó la necesidad de crear espacios de enseñanza superior en cine?, ¿cuáles fueron las posiciones y debates que atravesaron a los diferentes proyectos de enseñanza? Para dar respuestas a estos 
interrogantes es necesario inscribir el desarrollo de la institución cinematográfica en el marco del contexto sociocultural del país, ya que es en esa trama donde emergen y se configuran las significaciones sociales asociadas al cine.

\section{Algunas consideraciones históricas}

En el año 1951 se publica en Francia el libro La formación profesional de los técnicos de cine, de Jean Lods, realizador y cofundador del Instituto de Altos Estudios Cinematográficos (IDHEC). A excepción de países como la URSS o Italia que contaban ya desde temprano con instancias institucionales de enseñanza cinematográfica, ${ }^{1}$ la preocupación orgánica por los procesos de enseñanza aparece a partir de la Segunda Guerra Mundial en el marco de una fuerte crisis del conjunto de las cinematografías nacionales que motoriza interrogantes acerca del devenir de la actividad. En aquel libro Lods afirmaba: "Se olvida que los oficios cinematográficos, lo mismo desde el punto de vista técnico que artístico deben enseñarse como se enseñan el oficio del compositor, el pintor y el arquitecto" (Lods, 1951, p. 10). Una afirmación que se encuentra en absoluta sintonía con la aceptación ya generalizada del cine como un hecho cultural y artístico. Justamente sostiene Franco Casetti que en torno al año 1945 se presentan una serie de fenómenos nuevos que de a poco cambiarían las formas de la reflexión teórica sobre el cine. Uno de ellos es, claro está, la legitimidad que adquiere el cine en tanto medio de expresión; en segundo lugar, el carácter especializado que asume la crítica a partir de la aparición de publicaciones específicas donde se hace presente un nuevo tipo de lenguaje, separado del lenguaje común, para referirse a las producciones cinematográficas, y, por último, la internacionalización que adquieren los debates sobre cine.

En la Argentina, en línea con las tendencias globales, las primeras experiencias formales de enseñanza cinematográfica se desarrollan hacia fines de la década del cincuenta. Aunque habría que mencionar como antecedente inmediato y como principal agente que planteó la necesidad de la enseñanza formal del cine, a los cineclubs. Estos espacios adquirieron a partir de los años cincuenta, una importancia creciente, al funcionar como lugar de encuentro y de debate en torno al fenómeno fílmico. ${ }^{2}$ Allí se nucleaban personas procedentes de distintas áreas del campo cultural (teatro, plástica, literatura, filosofía) constituyéndose los cineclubs en una de las tantas formaciones culturales ${ }^{3}$ que se gestaron y participaron de la modernización cultural que transitó la sociedad argentina durante este período.

En torno a los cineclubs aparecen también las primeras publicaciones especializadas como la revista Gente de Cine, creada en 1951 por Rolando Fustiñana, Tiempo de Cine, editada por el cineclub Núcleo, Cuadernos de Cine, entre otras. Estas publicaciones acompañaron la renovación del campo del cine. O, en los términos del sociólogo Pierre Bourdieu, colaboraron en la gestación de un campo autónomo al instalar criterios de valoración propios y específicos para juzgar las obras, criterios que se encontraban en abierta tensión con las valoraciones ligadas a la industria del espectáculo. Se trata de revistas que se dirigen a un público restringido y que delinean los contornos de un nuevo perfil del crítico que se distancia por completo de la figura del cronista de espectáculos. ${ }^{4}$ La mayoría de estas publicaciones explicitan su deseo de formar a los nuevos realizadores y de crear conciencia cinematográfica en los espectadores. En línea con la consolidación de la modernidad en el cine (a partir de movimientos como la nouvelle 
vague, el neorrealismo italiano, y la polithique des auteurs impulsada desde la revista Cahiers $d u$ Cinema) estas publicaciones operan como canales de difusión de las nuevas teorías del cine que instalan un lenguaje propio y específico para abordar el universo cinematográfico.

La existencia de estos nuevos agentes (publicaciones especializadas, cineclubs y talleres) modifica sustancialmente el estatuto del cine. Como sostiene Bourdieu, la constitución de un campo relativamente autónomo de producción simbólica requiere de un medio social que sostenga la creencia en el valor cultural de dicho producto. Respecto al cine de autor, Bourdieu decía:

(...) fue necesario todo un universo social que permitiera el desarrollo del cine de autor: con pequeñas salas de proyección y cinematecas proyectando los "clásicos", frecuentadas especialmente por los estudiantes; cine clubes creados por profesores de filosofía entusiastas; críticos competentes, como los de Cahier $d u$ Cinema; y finalmente realizadores que aprendieron su oficio viendo y estudiando las películas que luego comentaban en Cahiers. Era necesario todo un medio social en el cual un cierto tipo de cine pudiera ser apreciado y reconocido (Tagesanzeiger, 1999).

En el país, como resultado de la presión ejercida por los diferentes grupos y en el marco de la profunda crisis que atravesaba el sector, ${ }^{5}$ se sanciona, en el año 1957 , la ley 17.741 conocida generalmente como la ley de cine. Entre otras reformas, y sobre la base de considerar al cine una práctica de naturaleza artística y un medio de difusión y educación de la cultura nacional, se crea el Instituto Nacional de Cinematografía (INC) y un Centro Experimental Cinematográfico destinado a la formación de cineastas que se puso en marcha recién en el año 1965.

Para ese entonces la educación cinematográfica ya había ingresado en el ámbito universitario. ${ }^{6}$ En el año 1956 se crea la emblemática Escuela Documental de Santa Fe, dependiente del Instituto Social de la Universidad del Litoral; en 1957 se hace efectivo el funcionamiento de la carrera de cine en la que fuera la Escuela Superior de Bellas Artes de la Universidad Nacional de La Plata y, en el año 1966, se aprueba la creación del Departamento de Cinematografía en la Escuela de Artes de la Universidad Nacional de Córdoba. La institucionalización de la enseñanza estuvo motorizada por muchos de los referentes nucleados en torno a los cineclubs y las publicaciones de cine, muchos de ellos se habían formado en el exterior y a su regreso volcaron su experiencia en el armado de los cursos. ${ }^{7}$ En todos los casos, se comenzó con el dictado de seminarios en el marco de la extensión universitaria pero rápidamente, como producto de la fuerte afluencia de jóvenes y de las corrientes modernizadoras que guiaban las políticas de muchas de las universidades nacionales, se institucionalizaron como carreras de nivel universitario. Un acto que, siguiendo a Bourdieu, otorga legitimidad a un determinado cuerpo de saberes a la vez que supone la consagración de determinados individuos y por su intermedio de los criterios de selección que los sustentan y los habilitan para la enseñanza de esos saberes. Se trataba en este caso, de la consagración de la creencia en el valor cultural y artístico del cine que al mismo tiempo, establecía una demarcación y un descrédito respecto del cine comercial o de entretenimiento. Cabe señalar que este reconocimiento social del cine como un arte autónomo resulta coincidente con la aparición de la televisión que releva parcialmente al cine de su función de entretenimiento.

Los referentes de la generación del sesenta (Manuel Antín, Simon Feldman, Rodolfo Kuhn, 
David Kohon, Fernando Birri, José Martínez Suárez, René Mujica, Leonardo Favio, entre otros), agentes fundamentales en la gestación de los primeros espacios de enseñanza, compartían- más allá de sus diferencias estéticas-, el diagnóstico acerca del anquilosamiento que atravesaba la industria cinematográfica argentina, y apostaban todos a una renovación tanto en el plano estético y narrativo como en los esquemas de producción.

¿Qué discursos sobre el cine circulaban en los recientes espacios de formación? Sostiene Emilio Bernini que:

toda la historia del cine, vista en los espacios cerrados [a la circulación mercantil, sean los cineclubs o los recientemente creados espacios de enseñanza] aparecía como aquello que se oponía a lo que nuestra cinematografía, en bloque, no había hecho: el cine argentino no formó parte del cine universal que se veía, salvo excepciones (...) El acto mismo de ver el cine del mundo (...) ya articulaba una crítica al cine de la industria y del peronismo (Revista KM 111, 2000, pp. 71-72).

Ahora bien esto no supuso la extrapolación sin más de las tendencias extranjeras, como sostiene Bernini se trataba de encontrar una imagen propia y:

hallar esa imagen dependía tanto de las tradiciones cinematográficas extranjeras como de la "propia realidad" cuya negación los nuevos cineastas impugnaban a la imagen neutra del cine del peronismo: miraban el cine universal para fundar una imagen nueva pero que exprese la propia realidad (Revista KM 111, 2000, pp. 71-72).

Esta tensión entre lo propio y lo foráneo aparece señalada con claridad en el caso de Fernando Birri, quien decía:

no se trataba de hacer cine neorrealista en la Argentina pero sí de hacer entender- y sobre todo hacer sentir- hasta qué punto es necesario que el arte cinematográfico, en virtud de sus propios medios expresivos, se afiance en la realidad de las imágenes que caen bajo nuestros ojos (...)la realidad de esas imágenes no puede dejar de ser la realidad de nuestra misma región, de nuestra misma nación, de los temas y problemas que por ser regionales son también nacionales y en todos los casos urgentemente humanos (Birri, 1964, p. 19).

La Escuela Documental de Santa Fe, a diferencia del caso de La Plata, Córdoba y el CERC, tuvo un perfil estético y político bien definido. Fernando Birri tenía una mirada crítica acerca de la enseñanza artística, en sus palabras:

no creo en las escuelas de arte en abstracto, donde se ilusiona con enseñar meramente una técnica con prescindencia de los contenidos espirituales que a ésta dan sentido artístico y justificación cultural en el ambiente dentro del cual dicha escuela debe funcionar (Birri, 1964, p. 17). 
Por otra parte, la inscripción institucional dentro del Instituto Social de la Universidad del Litoral también aportaba un perfil propio, fuertemente ligado a las problemáticas sociales del país. Los proyectos de La Plata y Córdoba tuvieron, si se quiere, otro derrotero, los departamentos de cine se incorporaron dentro de las tradicionales escuelas de bellas artes en línea con las profundas transformaciones que sufrieron estas instituciones producto de la modernización cultural y la incorporación de nuevas perspectivas en torno al arte. La Universidad Nacional de La Plata había iniciado ya un proceso reformista que, entre otras cosas, reformuló la enseñanza decimonónica que se impartía en la Escuela Superior de Bellas Artes. En 1961 se producen modificaciones en los planes de estudio, la carrera de cine se convierte en una licenciatura, según lo expresan las gacetillas oficiales: "se formaliza una nueva carrera profesional: cinematografía que vincula en el más alto rango la concurrencia de las artes y las técnicas contemporáneas". 8 El caso de Córdoba fue similar, en 1961 asume al frente de la gestión de la Escuela Superior de Bellas Artes el arquitecto Bulgeroni e impulsa una serie de transformaciones que modifican fuertemente las características de la institución y la ponen "a tono" con el clima de modernización cultural de la época. Como primera medida se reemplaza la denominación de la institución por "Escuela de Artes", expresando la vocación de extraer al arte del universo romántico y elitista y extenderlo al conjunto de las manifestaciones socioculturales. En esa línea, se crean los Departamentos de Teatro y Cine y se modifican los planes de estudio de las Áreas ya existentes (Plástica y Música). Se amplían las actividades de extensión universitaria creándose el Cine Club Universitario, el museo universitario de plástica y el teatro estable de la universidad. Por último, el caso del Centro de Experimentación y Realización Cinematográfica (CERC) dependiente del Instituto Nacional de Cinematografía (INC), cuyo proyecto databa de la ley de cine del 57, entra en funcionamiento en el año 1965. Al igual que en los casos anteriores, la organización de la enseñanza del Centro estuvo precedida por una serie de cursos libres cuyos fines eran la difusión del quehacer cinematográfico. La organización de los cursos estuvo a cargo del profesor Jorge E. Cromberg y, al frente del dictado de los mismos se encontraban personajes como Manuel Antín, Domingo Di Núbila, Roland Fustiñana, Rodolfo Kuhn, Leo Sala, Carlos Latorre, Alberto Rodriguez Muñoz, Néstor Gaffet, Kive Staif y Oscar Hensen. Como producto de la gran afluencia de interesados (se inscribieron 736 alumnos), las autoridades del Instituto decidieron poner en funcionamiento el CERC que comenzó con el dictado de cuatro carreras: Dirección, Producción, Guión e Interpretación.

Cada uno de los espacios mencionados presenta especificidades propias vinculadas directamente a su inscripción institucional: en los casos de Córdoba y La Plata la carrera de cine se organizó en el marco de las facultades de bellas artes, en medio de un proceso de modernización y reformismo universitario que supuso, en el plano de la enseñanza artística, la incorporación de las tendencias provenientes de la Bauhaus. ${ }^{9}$ Pero también, y en lo que hace a lo específicamente cinematográfico, la institucionalización de la enseñanza del cine estuvo motorizada por agentes que, imbuidos del clima modernizador que caracterizó a los años sesenta, absorbieron las nuevas tendencias que caracterizaban al cine a nivel global y que, en los términos de Bourdieu, suponía la presencia de un mayor grado de autonomía de la práctica cinematográfica en la medida en que se distanciaba de la valoración estrictamente económica o comercial, dando lugar al desarrollo de un lenguaje propio y específico para juzgar y valorar los films.

Ahora bien, este proceso de autonomización se produce en el marco de una creciente politización de la sociedad que marcó los debates y el devenir del conjunto del campo cultural. Hacia 
mediados de la década del sesenta, especialmente a partir del derrocamiento del gobierno de Illia, los conflictos y las posiciones políticas de los miembros del campo intelectual se fueron radicalizando. Como señalan Longoni y Mestman, la política cultural del régimen se caracterizó por su orientación fuertemente autoritaria, durante el onganiato se cerraron publicaciones, se clausuraron salas teatrales, se impulsaron leyes que pusieron freno a la libertad de expresión, muchas universidades nacionales sufrieron intervenciones y se persiguieron espacios que como el Instituto Di Tella funcionaban como epicentro del "ambiente moderno". Como ellos mismos sostienen: "la misma dimensión autoritaria del régimen presiona hacia la unificación en un mismo lugar de oposición a diversos grupos culturales que asumieron en términos políticos más radicales su enfrentamiento al gobierno" (Longoni y Mestman, 2008, p. 37). Sin embargo, también provocó algunas fracturas. En relación al cine resulta de interés consignar una anécdota que narra Beatriz Sarlo en el libro La máquina cultural que ilustra la fractura que se establece entre vanguardia estética y vanguardia política. En 1970, producto de las recurrentes censuras y amenazas que pesaban sobre la Escuela Documental de Santa Fe, un grupo de docentes de esta viaja a Buenos Aires para establecer contactos con cineastas porteños y comprometerlos a colaborar en un acto a realizarse en la ciudad de Santa Fe. La decisión de los cineastas porteños, entre ellos Alberto Fischerman, Rafael Fillipell, Julio Ludueña fue llevar al acto una serie de cortometrajes, todos ellos realizados en un lapso muy breve de tiempo y con una fuerte carga experimental. En el marco del encuentro, conocido como Primer Encuentro Nacional de Cine, se exhibieron estos films que provocaron un acalorado debate entre los asistentes. Recordemos que ya al interior de la Escuela había una clara división entre los "birristas", partidarios del documental social puro, identificados con Fernando Birri y que tenían fuertes nexos con el Instituto de Cine Cubano y el Grupo Cine Liberación, y los "antibirristas" o esteticistas. La reconstrucción que realiza Sarlo muestra el grado de politización presente en el campo cultural en ese entonces y el acotamiento de las potencialidades de la autonomía en un contexto de autoritarismo, censura y persecución. Sarlo busca reivindicar el gesto de los cortos realizados por los referentes de la "movida cultural porteña" como un esfuerzo por mantener la tensión entre estética y política. En sus palabras:

estos films quisieron seguir examinando un camino que sus autores no consideraban clausurado: el de la relación intrincada entre dos lógicas y dos lenguajes. La política pedía intervenciones de contenido; estos filmes promovieron intervenciones formales consideradas en sí mismas, más radicales que los contenidos explícitos. Interesan (y conmueven) por lo que muestran como posibilidad que se cerró poco después... (Sarlo, 2007, p. 197)

La irrupción de la dictadura militar de $1976{ }^{10}$ puso fin dramáticamente a la vitalidad y el dinamismo que tuvo el campo cultural durante esos años. Las universidades fueron intervenidas, se cerró la carrera de cine de la Universidad Nacional de La Plata, lo mismo que los Departamentos de Cine y Teatro de la Universidad Nacional de Córdoba y la Escuela Documental de Santa Fe. Se daba inicio así a un nuevo capítulo en la historia del país que, más allá de la ilusión causada por la recuperación democrática, transformaría profundamente las características del campo cultural. 
¿Sobre qué tradiciones se estructuran los nuevos espacios de enseñanza? ¿Qué rol juegan éstos en la revitalización del campo del cine que se produce hacia fines de los años noventa?

Lo que nos interesa destacar hasta aquí -y que fue ya señalado por Sarlo y Altamirano refiriéndose a la aparición de la figura del escritor profesional a principios del s. XX-, es que la emergencia de un campo socialmente diferenciado no puede pensarse en forma aislada, es preciso integrarla en el contexto socio-político de la época. ¿Qué fuerzas intervinieron entonces en la institucionalización de la enseñanza cinematográfica?, ¿sobre qué horizonte discursivo tuvo lugar la profesionalización de quehacer cinematográfico?

El planteo acerca de la necesidad de crear espacios de educación cinematográfica no provino de la industria, sino de agentes que, influenciados por los movimientos cinematográficos europeos y rechazando el cine argentino existente, promovieron la búsqueda de nuevas formas estéticas, narrativas y de producción. Como mencionamos, la consolidación de los espacios de enseñanza consagró estas nuevas visiones acerca del cine, legitimando así la creencia en el valor artístico y cultural del mismo. Las universidades nacionales funcionaron como el espacio institucional indicado para inscribir estas nuevas miradas en la medida en que fueron protagonistas de los movimientos reformistas y modernizadores que caracterizaron la época. Y, finalmente, desde el Estado se acompañó este proceso al promulgarse la ley del año '57 que no sólo estipulaba la creación de un instituto con la misión de proteger y fomentar la producción nacional sino también, la creación de una escuela que, dependiente del mismo, sería la encargada de formar a los futuros profesionales, quebrando así la lógica escalonada de enseñanza dentro de la industria. Luego, la creciente politización de la sociedad condicionó fuertemente el devenir del campo cultural y sus debates.

\section{La recuperación democrática y la reconstrucción de los espacios de enseñanza cinematográficos.}

Durante los primeros años del gobierno de Alfonsín la educación y la cultura se convirtieron en áreas claves y estratégicas desde donde contribuir al desarrollo de una nueva cultura política fundada en valores democráticos que desterraran el autoritarismo instalado en la sociedad. Como sostiene Wortman:

en los últimos años de la dictadura comienza a generarse una reflexión de otro orden vinculada a la necesidad de intervención en el plano cultural, a partir del reconocimiento, no sin conflictos, de la demanda de constitución de un campo intelectual (Wortman, 2002).

En este marco de debates, una de las prioridades que se planteó Alfonsín al llegar al gobierno fue reconstruir los lazos y la dinámica del campo cultural como un motor fundamental para fomentar el desarrollo de una cultura democrática.

En lo que refiere a la política universitaria se inicia un proceso de normalización y modernización que implicó: la recuperación de los principios de autonomía y cogobierno; el cese de las restricciones en el ingreso a las universidades; la renovación del plantel docente por medio 
de concursos que garantizaran criterios meritocráticos de selección; el apoyo a la investigación científica que permitiera, por medio del otorgamiento de becas y subsidios, la formación continua del plantel docente; la creación de carreras de grado, entre otros temas.

En este contexto y en las áreas que nos competen se inauguran las carreras de Diseño Gráfico y Diseño Industrial en la Facultad de Arquitectura y Urbanismo incorporando los “diseños" dentro de dicha unidad académica; se crea la carrera de Ciencias de la Comunicación en el marco de la Facultad de Ciencias Sociales, ${ }^{11}$ se inaugura la especialidad de Artes Combinadas (cine, teatro y danza) en la Facultad de Filosofía y Letras y se inician acciones destinadas a motorizar la reapertura de las carreras de cine de las universidades nacional de La Plata y Córdoba que luego se extenderían a otras universidades nacionales.

Los deseos de participación expresados por la sociedad civil se vieron reflejados también en el dinamismo que adquirió en la escena cultural la aparición de revistas culturales, la actividad teatral y el cine fueron espacios que colaboraron en la reflexión y el debate sobre el pasado reciente. El gobierno, por su parte, incorporó en su equipo a importantes referentes del campo intelectual expresando la voluntad de trabajar intensamente en la reconstrucción dicho campo. $\mathrm{Al}$ frente del Instituto Nacional de Cinematografía (INC) asumió Manuel Antín y desde allí colaboró en la recuperación del prestigio del cine nacional tanto en el plano local como internacional. La primera medida fue abolir la censura que pesaba sobre el cine, y luego el esfuerzo se centró en recuperar la producción (durante esta etapa se alcanzó un promedio de 20 estrenos anuales); ganar prestigio a nivel internacional (se tejieron lazos con el circuito de festivales internacionales que propiciaron luego la realización de coproducciones) y fomentar la aparición de nuevas propuestas estéticas y de producción a través del impulso a las opera prima (entre 1984 y 1987 más de cincuenta realizadores consiguieron filmar su primer largometraje). El impulso que adquirió la actividad cinematográfica durante los primeros años de la democracia se vio expresado en un aumento sistemático de los aspirantes a ingresar al CERC: de los 80 postulantes que hubo en 1983 se pasó a 500 en el 1986 y a 900 en 1987. Al momento de la reapertura democrática el CERC era la única institución de carácter público que impartía una enseñanza formal en cinematografía.

Por último y en lo que refiere específicamente a las modalidades de trasmisión del quehacer cinematográfico es importante destacar la importancia que tuvo la aparición del video. El formato de video hizo posible el acceso a la experimentación y la práctica que muchas veces se veía imposibilitado por los altos costos del dispositivo cinematográfico. Por otra parte, el video hogareño también operó como un vehículo fundamental en la medida en que puso a disposición de las nuevas generaciones la historia del cine mundial que podía verse y reverse fácilmente. En cierta forma, el videoclub vino a reemplazar a la práctica cineclubista, fue un modo de aprender a ver, aunque con la salvedad, no menor, que acarrea su modalidad de consumo.

El conjunto de estos cambios, al tiempo que colaboró en la gestación del medio social que sería más tarde el vehículo para la reactivación de la cinematografía nacional (nos referimos al resurgimiento que implicó la aparición del denominado Nuevo Cine Argentino 12), fue también el obstáculo que tuvo la política cinematográfica del alfonsinismo. Como sostiene Aprea, la política cinematográfica del período se sostuvo sobre una concepción del "cine como actividad autónoma cuya única vía de circulación significativa eran las salas cinematográficas" (Aprea, 2008, p. 16). Hacia fines de la década se modifica sustancialmente el circuito de exhibición (única fuente de recaudación del INC) cerrándose innumerables salas de cine. ${ }^{13}$ El video ho- 
gareño, la televisión por cable y el predominio de films producidos por las grandes majors norteamericanas provocaron una caída notable del público de cine argentino.

La expansión del universo audiovisual no fue prevista por la política cinematográfica del gobierno de Alfonsín que continuaba regida por la ley promulgada en 1957. ${ }^{14}$ Sin embargo, el concepto de lo "audiovisual" fue adquiriendo cada vez mayor centralidad, aunando consensos en torno a la necesidad de establecer puentes entre el cine, la televisión y el video. Como sostiene Getino, la expansión de la industria audiovisual planteó un punto de inflexión para el cine cuya problemática "no podría ser resuelta en la especificidad de dicho medio, sino en sus relaciones con lo audiovisual". ${ }^{15}$ Estos eran los debates que atravesaban al sector hacia finales de la década anticipando lo que sería la nueva ley de cine que se sanciona en 1994. ${ }^{16}$

\section{Los años`90: la institucionalización de la enseñanza cinematográfica}

El clima optimista que se vivió durante los primeros años de la recuperación democrática se vio rápidamente atravesado por la ofensiva neoliberal que caracterizó a la década del noventa. En los ochenta las iniciativas vinculadas a la reconstrucción del campo cultural estaban directamente asociadas a su dimensión política, es decir, la educación y la cultura eran concebidas como espacios vitales para generar una nueva cultura política fundada en valores democráticos. Como sostiene Wortman: "el gobierno de Menen no desarrolló políticas culturales en un sentido estricto, pero sí fue exitoso (...) en la generación de nuevas representaciones sociales, nuevos imaginarios y nuevos valores" (Wortman, 2002).

Uno de los ejes fundamentales de la política menemista fue la privatización de esferas paradigmáticas del Estado. Nos interesa señalar brevemente lo sucedido en materia educativa y en el campo de los medios de comunicación.

Durante los años noventa se pusieron en marcha una serie de medidas en el área educativa que modificaron la tradicional relación entre el Estado y la Universidad. Dichas medidas quedaron plasmadas en la Ley de Educación Superior que se promulga en 1995, una ley que introduce cambios sustantivos en lo que refiere a los históricos conceptos de autonomía, financiamiento y gobierno universitario. Calidad, eficiencia, competencia, acreditación, evaluación pasan a ser palabras claves y recurrentes en las medidas que se ponen en marcha a través de dicha Ley, habilitando profundos debates en torno a la identidad de la universidad pública y su función social.17 Los principales rasgos de las transformaciones acaecidas en el sistema de educación superior fueron: una creciente expansión de la matrícula, una multiplicación y diversificación de las instituciones de enseñanza superior (tanto universitarias como no universitarias), una importante restricción de las inversiones estatales complementada por un incremento de la inversión proveniente del sector privado y una intervención creciente de las agencias internacionales en la definición de las políticas educativas.

No es el objetivo del artículo profundizar en las características del sistema de educación superior ni tampoco ahondar en las modificaciones que introduce la Ley, simplemente señalar, siguiendo a Mollis, que a partir de los años noventa, muchas de las políticas educativas, en cuanto a sus modalidades de la oferta, han contribuido a aumentar la fragmentación, desarticulación y segmentación del sistema, al orientarse exclusivamente a satisfacer las demandas de los potenciales consumidores. 
Estos cambios fueron el marco que posibilitó la notable expansión que se produce en la oferta de enseñanza audiovisual durante la década. Es difícil contar con datos sistematizados que revelen la evolución del área, tanto a nivel de la oferta como de la demanda, pero sí podemos saber, a partir del Censo Nacional Audiovisual realizado por el Instituto Nacional de Cinematografía y Artes Audiovisuales (INCAA) que al año 2005 había en el país 12.740 estudiantes repartidos en un total de 43 instituciones de enseñanza (universitaria y no universitaria). El 75 $\%$ de los mismos se concentran en la Capital Federal y la Provincia de Buenos Aires, le siguen luego, la provincia de Córdoba con el 19\% y Santa Fe con el 4\%, justamente ciudades que, junto a La Plata fueron pioneras en incorporar la enseñanza cinematográfica en el ámbito universitario. En relación a la modalidad de gestión de las instituciones, el 50 \% es de gestión privada, dato que se acentúa para el caso de la Capital Federal donde de las 17 instituciones existentes, 12 son privadas.

Existe otro factor, no menos importante, que es preciso tomar en consideración para completar el cuadro que estamos delineando. Nos referimos a uno de los aspectos de la tan mentada "postmodernidad" que se vincula al cuestionamiento o la deconstrucción de los grandes relatos que conformaron a la modernidad: verdad, razón, sujeto, historia ya no parecen tener la densidad ontológica de entonces. De ahí que las universidades, entendidas y reconocidas socialmente como instituciones productoras de conocimiento científico, es decir, conocimiento verdadero, se vean enfrentadas a un fuerte desafío que exige repensar su función social.

En paralelo crecen significativamente las carreras vinculadas a la comunicación, en línea con una cultura donde "lo verbal", y su densidad argumentativa va cediendo paso a la presencia creciente del universo de la imagen en la vida contemporánea. Como sostiene Devalle (Devalle, 2009), el problema de la imagen, de los géneros visuales y audiovisuales en tanto prácticas emergentes devenidas hegemónicas se convierte rápidamente en uno de los grandes ejes del debate y la reflexión por parte de las ciencias sociales generando consensos en torno a la existencia de una nueva cultura sostenida sobre la hegemonía visual.

El conjunto de estas transformaciones, si se quiere epocales, tomó en nuestro país un rostro propio resultado de las modalidades específicas en que fueron aplicadas las políticas neoliberales. Como sostiene Wortman, una de las llaves para comprender el relativo consenso que tuvieron las medidas implementadas durante el menemismo está ligado al lugar estratégico que tuvieron los medios de comunicación en el proceso de construcción de hegemonía. Muy brevemente, la serie de reformas estructurales aplicadas en el país redundaron en una apertura de los mercados que impactó de manera diferente y asimétrica en los distintos sectores de la economía. Este proceso, que supuso una concentración extrema del capital, fue instrumentado principalmente por la Ley de la Reforma del Estado con su sello privatizador, y por el Plan de Convertibilidad que, junto con el rol que tuvieron los medios de comunicación, fue uno de los elementos claves en el mantenimiento de la hegemonía durante esos años. La privatización de los cuatro canales del Estado en 1989 y la venta de ENTEL fueron las primeras señales por parte del gobierno de lo que ocurriría luego en materia comunicacional. Durante el menemismo la Ley de Reforma del Estado (No 23.696) se impuso sobre la Ley de Radiodifusión (No 22.285) modificándose todas aquellas reglamentaciones que, o bien limitaran la propiedad de las estaciones, prohibieran la fusión de grupos periodísticos y televisivos, frenaran la inversión extranjera, o impusieran regulaciones sobre la publicidad. Se verificaron así dos procesos: en primer lugar, un eslabonamiento transversal de distintos medios (canales televisivos, radios, 
revistas, diarios) en manos de un mismo grupo local (Clarín, Atlántida, América, Perfil), y luego la extranjerización del sector como resultado de las inversiones que se hicieron en el área de las telecomunicaciones, especialmente atractivas para la generación de rentabilidades. Así, quedaron conformados dos grandes conglomerados que concentraron el conjunto de las actividades del mercado ampliado de las telecomunicaciones: Grupo Agea/Clarín y el tándem CEI/TISA. Ciertamente este proceso implicó una modernización del sector y una mayor diversidad de la oferta. Pensemos por ejemplo en la aparición de la televisión por cable que aumentó notablemente la oferta televisiva obligando a mejorar la calidad de la televisión abierta. Ahora bien, la falta de regulación en materia de leyes antimonopolio, o mejor, la aplicación de políticas tendientes a beneficiar a unos pocos sectores con capacidad de lobby hizo que la modernización fuera acompañada, en materia de la propiedad del capital, por altos niveles de concentración. En lo que refiere a la industria del cine, ésta se encontraba atravesando una crisis profunda, los cambios en los hábitos de consumo, así como la extranjerización y concentración de los circuitos de exhibición y distribución dieron como resultado, en materia de número de estrenos nacionales, una de las peores cifras de la historia de la industria local: en el año 1992 se estrenaron apenas 10 películas nacionales. Esta situación, si se quiere agónica de la actividad, se modifica significativamente como resultado de la promulgación, en septiembre de 1994- de la nueva ley de cine. Esta ley es el resultado de la presión y reivindicación de diversos sectores ligados a la actividad que a partir de las transformaciones operadas en el conjunto del escenario audiovisual, exigieron la incorporación de la televisión y el video como fuentes de recaudación del Fondo de Fomento. Así, al tradicional 10 \% que se extraía de las entradas vendidas se sumó un gravamen similar por venta y alquiler de video pregrabado y un $25 \%$ de los ingresos que el Comité Federal de radiodifusión (COMFER) obtiene de la facturación de los canales por publicidad. Esto supuso un aumento significativo de los fondos destinados a promover la producción cinematográfica que redundó en la posibilidad de que muchos de los jóvenes que se venían formando dentro de los espacios de enseñanza cinematográfica pudieran producir sus primeras películas promoviendo así la reactivación del sector.

\section{Algunas reflexiones en torno a la enseñanza del cine en la actualidad.}

Lo señalado hasta aquí nos permite captar las fuerzas estructurales que operaron como habilitadoras de la expansiva oferta y demanda de la educación cinematográfica. Cambios en el sistema educativo que señalan, por un lado, la crisis de las carreras tradicionales y el crecimiento de la demanda de carreras vinculadas a la comunicación, y, a su vez, la expansión de la oferta de gestión privada que en el caso de la Ciudad de Buenos Aires tiene una importante presencia en lo que refiere a la educación cinematográfica. Pero además, la expansión de universo audiovisual en la cultura contemporánea presiona sobre el campo educativo al demandar profesionales aptos para ocupar posiciones dentro de un mercado laboral que, a la vez que presenta mayores posibilidades se encuentra, al menos hasta la puesta en práctica de la nueva ley de medios audiovisuales, altamente concentrado.

Ambos elementos ponen en escena la existencia de factores nuevos en los que se inscriben los espacios de enseñanza cinematográfica en la actualidad, que los distancian de la discursividad que envolvió a las iniciativas fundantes de fines de la década del cincuenta. 
A los fines de poder establecer comparaciones dejaremos de lado la oferta no universitaria cuyo perfil institucional no presenta contradicciones en la medida en que se ofrecen como tecnicaturas cuya misión consiste en dar respuestas a las demandas de un mercado en expansión. En el caso de las universidades, si bien se encuentran atravesadas por tensiones mercantiles (más aún a partir de las transformaciones mencionadas) éstas deben dar respuestas de índole disciplinaria o epistemológica frente al tipo de conocimiento que imparten.

En el caso de La Plata, uno de los debates que se hicieron presentes al momento de exigir la reapertura de la carrera de cine estuvo ligado al problema de su inscripción institucional. ¿Debía continuar la carrera en el marco de la facultad de bellas artes o debía enmarcarse en el horizonte de las recientemente institucionalizadas carreras de comunicación social? Según cuenta Carlos Vallina, protagonista junto a otros de las reivindicaciones por la reapertura de la carrera, ellos acordaban en inscribir al cine en el campo de la comunicación (siendo que ésta era inherente a todo proceso artístico-expresivo), pero dicha carrera ya se había creado y en ella la escuela de periodismo tenía un lugar protagónico. Más allá de las disputas de camarillas, lo interesante es recuperar la discusión de fondo en torno al arte y la educación artística. Señala Vallina:

Yo recuerdo que en la facultad de Bellas Artes se decía por ejemplo: "bueno, a ver si abrimos esta carrera y nos encontramos con que quieren ser Fellinis" (...) estos prejuicios (...) eran rémoras en algún sentido de la discusión de la década del setenta, básicamente sobre la esencia y función del cine: si tenía que ser un compromiso social o una experimentación artística... (Massari y otros, op. cit, p. 104).

Las discusiones se prolongaron hasta que finalmente en el año 1993, el Consejo Superior aprueba la creación de la carrera de Comunicación Audiovisual en el marco de la Facultad de Bellas Artes. ${ }^{18}$ En el diseño de la currícula participaron, entre otros, Octavio Getino quien insistía sobre la necesidad de pensar el cine en un marco más amplio, el nuevo mundo audiovisual, que suponía la formación de personas que no se dedicaran exclusivamente al cine (entendido como el largometraje de ficción) sino también al mundo audiovisual de la televisión, de servicios audiovisuales sociales, educativos y culturales.

Un proceso similar ocurre en el caso de la creación de la carrera de Diseño de Imagen y Sonido. Carrera fundada en el año 1989 en el marco de la Facultad de Arquitectura, Diseño y Urbanismo. Vale recordar que en el año 1985 se habían incorporado a dicha facultad la carrera de Diseño Gráfico y de Diseño Industrial, movimiento que se hace extensivo más tarde a Diseño de Imagen y Sonido y Diseño de Indumentaria y Textil. Más allá de los recorridos, muchas veces vinculados a trayectorias personales, que permiten comprender por qué fue la Facultad de Arquitectura quien cobijara a estas nuevas carreras, lo que interesa aquí es la disputa que tuvo lugar con la Facultad de Ciencias Sociales, concretamente con la carrera de Ciencias de la Comunicación. Una discusión que más allá de las disputas presupuestarias encierra una problemática epistemológica que aún no está resuelta y que merece ser pensada para que la universidad no se convierta en un espacio que da respuestas profesionalistas a las necesidades del mercado. En el informe que eleva la Carrera de Comunicación en el marco de las discusiones en torno al Proyecto de creación de la carrera de Diseño de Imagen y Sonido resuenan este tipo de interrogantes ¿bajo qué criterios se fundamenta la creación de nuevas carreras?, ¿ sobre la base 
de qué modelo de desarrollo?, ¿qué límites tienen proyectos como el de la FADU apoyados en el concepto de "diseño, el cual teóricamente puede ser extendido a cualquier campo del saber? Con el objetivo de evitar superposiciones y en el marco de iniciativas tendientes a fomentar la interdisciplinariedad, el proyecto de Diseño de Imagen y Sonido se pensó como un caso donde convivieran diferentes unidades académicas: la Facultad de Ciencias Sociales y la Facultad de Filosofía y Letras donde ya se encontraba en funcionamiento la carrera de Artes Combinadas, esta administración compartida no fue posible, aunque finalmente la carrera fue aprobada por el Consejo Superior y entró en funcionamiento a partir de una administración compartida entre la Facultad de Arquitectura y la Facultad de Filosofía y Letras. El perfil de la carrera es un tema en permanente debate, y conviven dentro de la carrera posiciones muy diversas que se expresan en las diferentes cátedras de Diseño Audiovisual. En cualquier caso, y como resultado de las transformaciones suscitadas en el campo de la comunicación audiovisual, entre los objetivos de la carrera- expresados en los documentos institucionales-, no hay referencia al cine como práctica autónoma. Se señala, en cambio:

mantener y propender a la elevación del nivel de grado en lo académico profesional de la carrera de Diseño de Imagen y Sonido, preparar profesionales que se conviertan en recursos humanos idóneos a participar en el extenso campo de los medios audiovisuales (...) Instalar la actividad audiovisual como disciplina proyectual. ${ }^{19}$

Por último, nos interesa hacer mención del caso de la Universidad del Cine (FUC) dirigida por Manuel Antín. Una universidad que, dadas sus características, adquirió una importante notoriedad a partir de lo que fue el fenómeno del Nuevo Cine Argentino. Se trata de una universidad de gestión privada que se funda en el año 1991, si pensamos en lo que era por entonces el campo de la educación cinematográfica, podemos decir que tuvo la particularidad de ser pionera al instalar la importancia de la enseñanza de nivel superior en cine. Un acto que logró distinguirla, tanto frente a la oferta vinculada a las tecnicaturas, como a la de los espacios universitarios vinculados a la comunicación y el diseño. Referido a esto, el crítico David Oubiña señalaba en una entrevista que: "la diferencia cualitativa de la Universidad del Cine [FUC] fue que se planteó como una universidad de directores, acá vienen los directores a estudiar cine.” En este sentido, la figura de Antín funcionó delineando un perfil de la institución que la convierte en heredera del movimiento moderno de la década del sesenta, con su reivindicación autoral del cine.

\section{Reflexiones finales}

Este extenso derrotero por la historia de la enseñanza cinematográfica nos permite vislumbrar en primer lugar, la importancia que tiene inscribir estos procesos en el marco sociohistórico en el que tienen lugar, sólo así resulta posible advertir las líneas de fuerza y las tensiones que los atraviesan, así como las resignificaciones de las diferentes posiciones en juego. En ese sentido nos interesa detenernos sobre un punto que marca tanto continuidades como rupturas. Hacia fines de los años 60 el campo cultural se vio atravesado por un conjunto de debates vinculados 
a la función social del arte. En el caso del cine, como vimos, la anécdota que reconstruye Beatriz Sarlo acerca del Primer Encuentro Nacional de Cine realizado en Santa Fe en 1970 resulta por demás significativa y sirve para ilustrar además, los debates en que se hallaban inmersas las recientemente creadas carreras de Cine, nos referimos a la tensión entre vanguardia estética y vanguardia política. A partir de los ochenta se recuperan estas discusiones pero resignificadas a partir de un nuevo contexto signado por la expansión del universo audiovisual en la cultura contemporánea. En este contexto, las posiciones que defienden la función social del cine, que en otro tiempo, reivindicaban al cine político, hoy aparecen representadas a través de las voces que plantean la necesidad de pensar al cine en el marco del expandido universo audiovisual; se trata de una posición que podemos identificar claramente a partir de la trayectoria del propio Getino. Estas posiciones que en cierta forma abandonan la reivindicación de la autonomía del cine corren el riesgo de quedar sujetas a las tensiones mercantiles que el nuevo contexto, sin dudas, plantea. Pero a su vez, y en vistas a la recientemente promulgada ley de medios audiovisuales da cuenta del rol que aún tienen las instituciones universitarias a la hora de generar pensamiento crítico que, como en este caso, ponga en discusión tanto la concentración mediática como el, en ocasiones, indiscutido rol de entretenimiento que se le adjudica a los medios de comunicación.

\section{Notas}

1. En 1920 se inician los cursos en El Instituto Estatal de Cinematografía en Moscú y en 1935 se funda, en Roma, el Centro Experimental de Cinematografía, las iniciativas se vinculan al interés institucional que despierta el cine por su enorme potencial de penetración ideológico-cultural. 2. A los cineclubs ya existentes como el Cine Club Argentino y el Cine Club Gente de Cine se sumaron otros como el emblemático Cine Club Núcleo fundado en 1954 por Salvador Sammaritano, hasta crearse la Federación Argentina de Cineclubs que adquiere estatuto legal en 1955, señal de la importancia que adquieren dichos espacios. Para mayor información al respecto, véase La generación del 60 de Simon Feldman.

3. Raymond Williams emplea dicho término para referirse a los movimientos y tendencias de la vida intelectual que ejercen influencia en la vida cultural de una época.

4. Para mayor información acerca de la historia de las publicaciones cinematográficas puede consultarse el libro Páginas de Cine, compilado por Clara Kriger.

5. En el año 1957 se estrenaron sólo 15 películas nacionales frente a un total de 697 de origen extranjero.

6. Recordemos que las universidades fueron agentes claves en la modernización cultural que atravesó el país. En 1958 se crea la editorial de la Universidad de Buenos Aires (EUDEBA), se institucionalizan las ciencias sociales modernas, creándose las carreras de psicología y sociología, se crea el Consejo Nacional de Investigaciones Científicas y Técnicas (CONICET) entre otras medidas que marcan la presencia de una nueva concepción sobre el saber y el conocimiento que tiene lugar en el marco de la política desarrollista.

7. Fernando Birri y Adelqui Camusso se formaron en el Centro Experimental de Cinematografía, en Italia, ambos estuvieron al frente de la Escuela Documental de Santa Fe; Simon Feldman, referente de la generación del sesenta, docente y autor de diversos artículos sobre enseñanza cinematográfica lo hizo en el Instituto de Altos Estudios Cinematográficos, en Francia, junto a 
otros protagonistas del cine de este período como Humberto Ríos y Mabel Itzcovich. 8. Este fragmento de la gacetilla oficial es recuperado por Massari, Peña y Vallina (2006), Escuela de Cine. Universidad Nacional de La Plata. Creación, rescate y memoria, Ed. de la UNLP, La Plata, p 19.

9. Ricardo Marín Viadel distingue cuatro modelos históricos de enseñanza artística que si bien se desarrollan históricamente muchas veces conviven y se superponen en los centros de enseñanza: el taller de artista (dependiente del ámbito laboral), la academia de bellas artes (espacio escolar independiente donde se aprenden los fundamentos teóricos y prácticos del arte sin los cuales no es posible llegar a crear una obra de arte), la Bauhaus (espacio escolar independiente donde se conoce y experimenta con los elementos básicos del lenguaje plástico para formar a los profesionales en artes visuales) y el modelo del genio y la creatividad (niega la escolarización al sostener que no hay conocimientos que el artista deba conocer, para crear sólo es necesario hacerlo). Al respecto véase Marín Viadel "Enseñanza y aprendizaje en Bellas Artes: una revisión de los cuatro modelos históricos desde una perspectiva comparada" disponible en http://revistas.ucm.es/bba/11315598/articulos/ARIS9797110055A.PDF

10. Cabe aclarar que unos años antes, luego de la muerte del General Perón, la Universidad ya se había convertido en el blanco preferido de las acciones paramilitares comandadas por Lopez Rega. 11. La carrera de Ciencias de la Comunicación se inaugura oficialmente en el año 1986 bajo la órbita del rectorado y se incorpora finalmente a la Facultad de Ciencias Sociales en 1989. La propuesta de crear dicha facultad venía discutiéndose desde la reapertura democrática, siguiendo el ideal interdisciplinario y modernizador que guió los debates en materia de política universitaria. 12. Sobre las características del Nuevo Cine Argentino puede consultarse el libro Otros mundos de Gonzalo Aguilar donde se analizan los films en tanto cifras que permiten captar algunas de las transformaciones operadas en la sociedad argentina. Para un análisis sociológico del fenómeno puede consultarse también el libro Una década de Nuevo Cine Argentino (1995-2005), industria, crítica, formación, estéticas, compilado por Ignacio Amatriain.

13. De las más de 2000 salas que funcionaban en el país en los años setenta se llegó a un mínimo de 280 en 1992, año en el que se registra el número más bajo de estrenos cinematográficos.

14. Es interesante al respecto el señalamiento de Gustavo Aprea: "el gobierno gestionó los principales canales televisivos durante todo el período. Se produjo de esta manera una paradoja por la que bajo un mismo control gubernamental las dos partes del sistema de medios audiovisuales argentinos actuaban de manera separada e incluso contrapuesta”, Veáse Aprea, op.cit. pág. 16. 15. En octubre de 1988 se organizó en la ciudad de Buenos Aires el "Foro del Espacio Audiovisual" cuyo documento final expresa que los medios de comunicación audiovisual requieren de políticas integrales, dejando entrever que la problemática del cine no podía resolverse partiendo de la especificidad del medio sino en sus relaciones con lo audiovisual. Véase, Getino, O. (2005), Cine argentino entre lo posible y lo deseable, Buenos Aires, Ediciones Ciccus, p. 112 . 16. La nueva legislación (24.377) modificó el nombre del Instituto que pasó a denominarse Instituto Nacional de Cinematografía y Artes Audiovisuales (INCAA); supuso además el reconocimiento de la multiplicidad de formas de circulación del material cinematográfico modificando los mecanismos de recaudación del organismo estatal. Al tradicional 10\% que se extraía de las entradas vendidas se sumó un gravamen similar por venta y alquiler de video pregrabado y un $25 \%$ de lo que recauda el Comité Federal de Radiodifusión (COMFER) por las exhibiciones televisivas de películas nacionales. La nueva legislación, al ampliar notablemente los recursos 
del INCAA, resultó un aliciente importante para la producción fílmica, que pasó de 11 películas en 1994 a 36 en 1996.

17. Al respecto véase Buchbinder, P. (2005); Historia de las Universidades Argentinas, Buenos Aires Ed. Sudamericana; Mollis, M. (2001), La Universidad Argentina en tránsito. Buenos Aires, FCE. 18. La carrera de Comunicación Audiovisual cuenta con tres orientaciones: Licenciatura en Cine y TV, Licenciatura en Investigación y Planificación Audiovisual y Profesorado en Comunicación Audiovisual.

19. Extractos de la misión de la carrera, disponibles en www.fadu.uba.ar/academica/car_dis.html.

\section{Lista de Referencias Bibliográficas}

Aguilar, G. (2006). Otros mundos. Un ensayo sobre el nuevo cine argentino. Buenos Aires: Santiago Arcos Editor.

Altamirano, C., Sarlo, B. (1997). Ensayos Argentinos. De Sarmiento a la vanguardia. Buenos Aires: Ariel.

Amatriain, I. (comp.) (2009). Una década de Nuevo Cine Argentino (1995-2005). Industria, crítica, formación, estéticas. Buenos Aires: Ciccus.

Aprea, G. (2008). Cine y políticas en Argentina. Continuidades y discontinuidades en 25 años de democracia. Buenos Aires: Ed. Universidad Nacional de General Sarmiento, Biblioteca Nacional.

Bernades, H., Lerer, D., Wolf, S. (comp.) (2002). Nuevo Cine Argentino. Temas, autores y estilos de una renovación. Argentina: Fipresci.

Bernini, E. (2000). Ciertas tendencias del cine argentino. Notas sobre "el nuevo cine argentino" (1956-1966). Revista KM 111, No 1, pp. 71-72.

Birri, F. (1964). Escuela Documental de Santa Fe. Santa Fe: Editorial Documento Universidad Nacional del Litoral.

Bourdieu, P. (2003b). Campo de poder, campo intelectual. Buenos Aires: Quadrata.

(2003a). Creencia artística y bienes simbólicos. Elementos para una sociología de la cultura. Buenos Aires: Aurelia Rivera.

Buchbinder, P. (2005). Historia de las Universidades Argentinas. Buenos Aires: Ed. Sudamericana. Casetti, F. (1994). Teorías del cine. 1945-1990. Madrid: Cátedra.

España, C. (director) (1994). Cine argentino en democracia, 1983-1993. Buenos Aires: Fondo Nacional de las Artes.

Devalle, V. (2009). La travesía de las forma. Emergencia y consolidación del Diseño Gráfico (19481984). Buenos Aires: Paidós.

Feldman, S. (1990). La generación del 60. Buenos Aires: Ed. Legasa.

Getino, O. (2005). Cine argentino entre lo posible y lo deseable. Buenos Aires: Ediciones Ciccus.

Kriger, C. (2003). Páginas de Cine. Buenos Aires: Archivo General de La Nación.

Lods, J. (1951). La formación profesional de los técnicos de cine. París: Unesco.

Longoni, A., Mestman, M. (2008). Del Di Tella A “Tucumán Arde”. Vanguardia artística y política en el 68 Argentino. Buenos Aires: Eudeba.

Marín Viadel, R. (1997). Enseñanza y aprendizaje en Bellas Artes: una revisión de los cuatro modelos históricos desde una perspectiva comparada. Revista Arte Individuo y Sociedad, No9.

Massari, R., Peña, F., Vallina, C. (2006). Escuela de cine. Universidad Nacional de La Plata. Crea- 
ción, rescate y memoria. La Plata: Ed. UNLP.

Mollis, M. (2001). La Universidad Argentina en tránsito. Buenos Aires: FCE.

Peña, F. (editor) (2003). Generaciones 60/90. Buenos Aires: Museo de Arte Latinoamericano de Buenos Aires.

Perelman, P. y Seivach, P. (2003). La industria cinematográfica en la Argentina: entre los límites del mercado y el fomento estatal. Buenos Aires: Observatorio de Industrias Culturales, No 1.

Sarlo, B. (2007). La máquina cultural. Buenos Aires: Seix Barral.

Williams, R. (2000). Marxismo y Literatura. Barcelona: Península.

Wortman, A. (2002). Vaivenes del campo intelectual político cultural en Argentina, en Mato, D. (comp.). Estudios y otras prácticas intelectuales latinoamericanas en cultura y poder, Caracas: Consejo Latinoamericano de Ciencias Sociales.

\section{Recursos Electrónicos}

Diario Tagesanzeiger (8 de diciembre de 1999). Disponible en: http://docentes.uacj.mx/museo digital/cursos_2009/sarahu/puede\%20aun\%sobrevivis.pdf.

Facultad de Arquitectura, Diseño y Urbaismo (UBA). Disponible en: www.fadu.uba.ar/acade mica/car_dis.html.

Marín Viadel, R. (1997). Enseñanza y aprendizaje en Bellas Artes: una revisión de los cuatro modelos históricos desde una perspectiva comparada. Revista Arte Individuo y Sociedad, No9. Disponible en http://revistas.ucm.es/bba/11315598/articulos/ARIS9797110055A.PDF

Wortman, A. (2002). Vaivenes del campo intelectual político cultural en Argentina, en Mato, D. (comp.). Estudios y otras prácticas intelectuales latinoamericanas en cultura y poder, Caracas: Consejo Latinoamericano de Ciencias Sociales. Disponible en www.globalcult.org.ve/odf/ Wortman.pdf.

Summary: The teaching of cinema has already took its place in the field of superior education: the degree in Audiovisual Communication and the career of Image and Sound Design coexist, not without tension, with the already institutionalized carrees of Social Communication. Within the field of the studies on cinema, teaching has not been specially boarded; the present article looks for to approach to this thematic drawing up a history of the cinematographic education in the country in order to identify continuities and ruptures. It will also contribute to understand, on the basis of the partner-historical inscription of this process, the new significants related to cinema teaching.

Key words: audiovisual - cinema - education - university.

Resumo: La enseñanza del cine ha adquirido ya un lugar dentro del campo de la educación superior: las licenciaturas en Realización de Cine y TV, el Diseño de Imagen y Sonido convivem, não sem tensões, com as já institucionalizadas carreiras de Comunicação Social. Dentro do campo dos estudos sobre cinema, o ensino não foi um tópico especialmente abordado, o presente artigo procura aproximar-se ao tema a partir de traçar uma história da educação cinema- 
tográfica no país que permita identificar continuidades e rupturas, e compreender, em base à inscrição socio-histórica deste processo, as resignificaciones unidas ao ensino do cinema sendo que é nessa trama onde emergem e se configuram as significações sociais vinculadas ao cinema.

Palavras chave: audiovisual - cinema - ensino - universidade. 